\title{
Towards a sustainable Open Access monograph publishing workflow for academic institutions
}

\author{
Antonia C. Schrader*, Alexander Grossmann, Michael Reiche
}

Hochschule für Technik, Wirtschaft und Kultur Leipzig - Leipzig University of Applied Sciences, 04277 Leipzig, Germany

\section{Abstract}

Across the world, there is a growing interest in Open Access (OA) publishing. Therefore, OA publishing has become a trend and is of key importance to the scientific community. However, observing the publication landscape in Germany leads to a striking finding of very different approaches. In particular, $\mathrm{OA}$ book publishing is still in relatively early stages, leading to $0 \mathrm{~A}$ books being much less frequently published than $0 \mathrm{~A}$ journal articles. However, although well-established publishers offer the publication of OA books, only certain researchers can actually publish, because of high Book Processing Charges (BPCs). In contrast to such publishers, university presses publish books as OA without any or at significantly lower charges; however, university presses are often inadequately staffed and do not have the technical know-how of the state-of-the-art publishing of OA books possessed by well-established publishers.

For these reasons, our research project aims to develop an ideal and transferable publication workflow for $\mathrm{OA}$ books that is both cost-effective and personnel-efficient as well as media-neutral to enable universities to publish their publications as $0 \mathrm{~A}$.

To this end, a one-day meeting with stakeholders of the publication landscape was held in June 2018 at the University of Applied Science in Leipzig, Germany. During the meeting, the stakeholders were asked to present their views on the current situation and also the lessons learned and the shortcomings of the existing approaches.

As a result, the observation was confirmed that the publication landscape is very heterogeneous and that there are no standardised interfaces and no harmonised practices for publishing OA books. Furthermore, in a discussion with the stakeholders during the second part of the meeting, further various issues of $0 \mathrm{~A}$ book publishing were revealed that have to be considered. Additionally, the various challenges and wishes of the stakeholders could be classified into five topic areas.

* Corresponding Author 
These findings illustrate that the primary task of the research project has to be the analysis of the existing publishing workflows and abstracting generally valid processes that are needed to publish OA books. Additionally, the further issues of OA book publishing, mentioned by the stakeholders, have to be addressed during the development. The five topic areas will help reduce the complexity of this project.

Keywords: open access, monographs, OA monographs, publishing, workflow, stakeholder, books, university press, academic library, research project, gold open access

\section{Introduction}

The importance of timely, transparent and sustainable dissemination of the outcomes of academic research has increased enormously in recent years. Open Access $(0 \mathrm{~A})$ publishing provides the widest possible global dissemination channel by making academic research freely available online everywhere to everyone with no payment restrictions. However, while $0 \mathrm{~A}$ has been established as a trend among journals, it remains in the relatively early stages in book publishing. ${ }^{1}$

The percentage of $0 \mathrm{~A}$ publications in journals or single contributions in anthologies far outweighs the number of $0 \mathrm{~A}$ books. Currently, there are 11,802 pure $0 \mathrm{~A}$ journals worldwide, and more than 3 million journal articles are freely available as $0 A{ }^{2}$ On the other hand, the number of books published as $0 A$ is only 12,591 titles worldwide. ${ }^{3}$

This disparity is related to the fact that $\mathrm{OA}$ has been increasingly spreading in the subject areas of sciences, technology and medicine (STM) since $2002^{4}$, because it is common to publish journal articles in these subject areas. In contrast, significantly fewer results are published as $0 \mathrm{~A}$ in the fields of humanities, social sciences and law due to the tradition of publishing academic findings instead as monographs or editions. ${ }^{5}$ This tradition continues to prevail, although the Swiss National Science Foundation's (SNSF) recently published final report of OAPEN-CH confirms that "a digital edition that is freely available on the Internet increases the trackability, visibility and use of monographs". Additionally, it was revealed that "Open Access does not have a negative impact on printed book sales"7.

Another reason that fewer $\mathrm{OA}$ books are published could be that the production of an $0 \mathrm{~A}$ book differs in several aspects from the publication of a non-OA book. This includes, among other things, the choice of the CC license and the allocation of Document Object Identifiers (DOI), long-term archiving requirements and metadata dissemination.

\footnotetext{
1 see Collins and Milloy, 2016, p.21.

2 see Directory of Open Access Journals, 2018.

3 see Directory of Open Access Books, 2018.

4 see Ware and Mabe, 2015, p. 89.

5 see 0jennus, 2017, p. 81-92.

$6 \quad$ Ferwerda, Snijder et al., 2018, p. 7.

7 Ferwerda, Snijder et al., 2018, p. 7.
} 
In addition, there are technical challenges that have to be faced. As $0 A$ has been making strides in the journal market since the 2000s, standards for digital and media-neutral publishing have already been established. ${ }^{8}$ This is in contrast to book publishing, where publishers often refuse to implement XML in their production processes. Therefore, most academic books are usually published only as PDF files, which both complicates long-term archiving and significantly limits the dissemination of the books. Moreover, high charges from 1,000€ to over 15,000€ for publication of an 0A book by certain key players in the traditional book market are a massive obstacle to the majority of scientists. These so called Book Processing Charges (BPC), corresponding to Article Processing Charges (APC) of journals, represent the price tag for the publisher's service and could be paid by the authors themselves, the researcher's university, foundations or even libraries. ${ }^{9}$ However, so far there are only a few institutions or libraries in Europe that fund $O A$ books, which results in only researchers who attain certain levels of funding being able to actually afford to publish as $0 A$.

In conclusion, the lack of funding possibilities and the high BPCs of mainstream publishers hinder the development of $\mathrm{OA}$ book publishing.

For these reasons, existing university presses have already been taking steps in $\mathrm{OA}$ to become independent from traditional publishers. This is rational because universities usually are the institutions where scientists develop new research results and prepare them for publication. Furthermore, it is typical that academic specialists of universities conduct the peer-review process as part of editorial quality assurance. However, establishing a successful OA franchise is a tall order, and the majority of university presses do not have both the technical and financial know-how to do so. As a result, only a small fraction of university presses publish $0 \mathrm{~A}$ research, often with grave restrictions regarding the license, the variety of formats, etc. ${ }^{10}$

Moreover, the libraries, university presses and publishing houses that attempt to establish more or less automated $0 \mathrm{~A}$ publishing workflows do so in several ways. According to our observations, a highly heterogeneous infrastructure is currently developing that lacks standardised interfaces and harmonised practices.

For these reasons, our research project aims to develop an ideal and transferable publication workflow for $\mathrm{OA}$ books that is both cost-effective and personnel-efficient as well as media-neutral to enable universities to publish their publications as $0 \mathrm{~A}$ without the restrictions mentioned above. The workflow should be state-of-the-art regarding the technical possibilities and support the widest possible dissemination and accessibility by publishing e-books and printed books simultaneously. However, developing an ideal publication workflow is a tall order and should not be done alone.

Because of this, we decided to involve the primary stakeholders of the real-world OA publishing landscape in our research. To this end, a one-day meeting with the stakeholders described below was held in June 2018 at the University of Applied Science in Leipzig, Germany. The present paper summarises the results of the meeting.

8 see Uniform requirements for manuscripts submitted to biomedical journals, 2018, p. 42.

9 see Ferwerda, 2014, p. 35-38.

10 see Vogel and Kupferschmidt, 2017. 


\section{Method}

Because of the heterogeneity of the field of research with many more or less independent players, the method of a stakeholder meeting was used. As stakeholders of the publishing landscape and thus as key stakeholders for our research project, the following five groups were identified in advance:

1.) University presses: University presses can benefit, in particular, from the development of a cost-effective, staff-efficient and media-neutral publication workflow for OA books. In addition, several university presses in Germany already ensure the freely accessible publication of books of researchers and scientists of their institutions. Because of that, they can contribute significantly to the research project's objectives.

2.) Academic libraries: Academic libraries are the key players in dissemination of and making $0 A$ books accessible and visible to the recipients; therefore, they can provide important requirements for the workflow.

3.) Service provider: The service provider group represents, in general, important partners in the publication of academic books. Additionally, they currently offer academia-focused services related to publication of $O A$ content to long-established publishers as well as university presses.

4.) $O A$ funding institutions: $O A$ funding institutions offer various funding approaches that spread the costs of publishing $0 \mathrm{~A}$ books, so that all stakeholders can afford to publish or use $0 \mathrm{~A}$ content. That is another major requirement when developing the workflow.

5.) Established academic publishers: Last but not least, well-established academic publishers are of great importance to the development of a transferable publication workflow. After all, they have significant expertise in the efficient and quality-assured publication of books due to their mostly long histories.

Accordingly, 19 participants were invited from these five stakeholder groups. The meeting's aim was to gather both information about the different views on the current situation and lessons learned and existing deficiencies. We also aspired to determine if our observation regarding the publication landscape was true. In addition, the meeting's purpose was to add further questions in need for research to our research project to be able to develop an ideal publication workflow.

To meet these aims, the stakeholders were asked to give short pitch presentations, explain their visions of the story and also address the current challenges and wishes regarding the publication of $O A$ books during the first part of the meeting.

The information gathered from the pitch presentations served as input to a moderated discussion. In this second part of the meeting, the challenges and other topics were collected on flashcards, assigned to topic areas and discussed to develop a more consistent vision of challenges of an abstract workflow model of $\mathrm{OA}$ publishing. The findings from the pitch presentations and discussion are explained in the following chapter. 


\section{Results}

As just mentioned, the meeting consisted of two parts: the pitch presentations for the purpose of obtaining an overview of the publication landscape and the experiences of the stakeholders, and, in the second part, an open discourse with the objective of collecting both the challenges of publishing $\mathrm{OA}$ books and questions that had to be answered before it was possible to develop an ideal workflow.

\section{Pitch Presentations}

The participants' pitch presentations revealed how heterogeneous the publication landscape actually was. This became particularly clear during the presentations of university presses. Their approaches differed in the following aspects.

\section{University Presses}

\section{Corporate structure}

Some university presses offer their publication services as an extension of the university library and share the organisational infrastructure, while others are organised as affiliated institutes. The latter means that they are legally independent organisations that are active in a specific research field - in our case, publishing - and thus extend the range of a university's achievement ${ }^{11}$.

However, there are further models, e.g., university presses that are founded as limited companies (GmbH in Germany). This form of organisation leads to obligations that are completely different from those in the case of other forms mentioned above, such as the preparation of a balanced annual account.

Consequently, various corporate structures have to be considered and may lead to modifications of the planned workflow.

\section{Service levels}

University presses differ significantly in their service level agreements. All participating university presses offer slightly different services. Such service offerings range from full-service packages that include copy-editing, typesetting and laying out in-house or by a service provider that is assigned by the university presses, to the author's obligation to submit a camera-ready copy of the manuscript, with the university press 'only' organising the printing and distribution.

Furthermore, some university presses provide templates and/or author guidelines to support the author in making his or her manuscript ready for printing.

Similarly, several university presses mentioned that they maximized dissemination, visibility and impact of $0 \mathrm{~A}$ books by providing their OA books to discovery services, such as Google Books or DOAB, while others only create metadata for library catalogues and the national distribution.

Additionally, it was striking to learn that all participating university presses published only PDF files, while there are other university presses that offer various digital formats, such as EPUB and HTML.

11 see Humboldt-Universität zu Berlin, 2018. 


\section{Publishing philosophy}

In the project, publishing philosophy signifies how the university press is positioned. Does the university press position itself as a pure $0 \mathrm{~A}$ publisher with the authors' obligation to publish as $0 \mathrm{~A}$ (a minority of the participating university presses let the author decide whether he or she wants to publish as $O A$; at the others, it is obligatory), and is it possible to publish hybrid-style, i.e., publishing the $0 \mathrm{~A}$ content both as electronic and printed versions via print-on-demand (all participating university presses offer this service)?

Furthermore, the university presses' pitch presentations show that the organisation of $0 \mathrm{~A}$ books could be differentiated between publications that are organised in series and those that are not.

\section{Peer Review and Quality Assurance}

In principle, university presses vary in whether they organise a peer review or request a proofread manuscript from the author and 'only' ensure the quality of the technical and structural aspects of the manuscript. In our case, a minority of the participating university presses request a proofread manuscript from the author. The other presses ensure the quality of content using internal reviewers, the series editors, an editorial board or by a standardised double-blind peer review.

\section{Software usage}

The majority of the participating university presses do not use any software to support their production process, although open source software such as Open Monograph Press ${ }^{12}$ for the production of $\mathrm{OA}$ books already exists. Only one institution stated that they used an open source workflow management system. The common way of managing the manuscript submission was by website and via an online form or via email.

\section{Price Structure and Finances}

The pitch presentations were clear on that it was common for the authors to bear the costs of publishing. Additionally, it was uncommon for authors to receive royalties for publishing because most university presses supported economic interests. Usually, the university presses use the revenues from the printed and sold books to finance reprints and the purchase of ISBN numbers, or to support the universities' household buget. Sometimes, BPCs for the production of electronic versions of OA books and for the printed version, the printing cost as well, are charged. However, in other cases, purely electronic publication is free of charge.

\section{Legal issues}

All university presses published electronic OA books under Creative Commons licenses. However, university presses differed in restricting the choice of a Creative Commons license. While some of them published under CC-BY 4.0, which is one of the most 'open' licenses, others limited the publication by CC BY-NC-ND. The majority of university presses use various licenses or let the author choose. In addition, some presses claim the exclusive right of use for the printed version of a book.

12 see Open Monograph Press, 2018. 
It could be stated that there are big differences in the publishing process among university presses. However, the established academic publishers, academic libraries, service providers and $0 \mathrm{~A}$ funding institutions also face the challenges of $O A$ differently, which will be illustrated in the following chapter.

\section{Established academic publishers}

Three representatives of established academic publishers participated in the meeting in June. These three publishers are significantly different in their approach to $0 \mathrm{~A}$, once again illustrating a heterogeneous publication landscape.

One of the participating academic publishers is one of the most successful German publishers and published OA books and journals since 2005 alongside traditional monographs, anthologies and academic journals. According to the Directory of Open Access Books (DOAB), it is already one of the largest independent publishers of OA books.

In contrast, the second participating academic publisher is still beginning to include $0 \mathrm{~A}$ in its business model. The publisher predominantly publishes books in the humanities in various formats (PDF, EPUB and hardcover) but has not yet published OA books. However, it is already working on establishing a publication workflow for $\mathrm{OA}$ books to thus be able to offer $\mathrm{OA}$ from the very beginning and without any extra charge.

The situation is quite different with the third publisher that is already an established player in the linguistics community. The publisher offers free publication of OA books without any cost to the respective author. Furthermore, 'Open' to the publisher means not only free publication and dissemination of academic content but also the opening of the peer review process to the community (through Open Peer Review \& Community Proofreading).

\section{Academic libraries}

As already mentioned, libraries are important stakeholders in OA publishing. They are the information brokers and distributors and connect publishers and researchers. In addition, they are the key actors that make $\mathrm{OA}$ content accessible and visible. A representative of the stakeholder group academic library participates in the management of the library of the University of Applied Science Leipzig. During the meeting, the management of the library expressed its awareness of its important role in $\mathrm{OA}$ publishing. At present, the management is working on developing the necessary structures and an $0 A$ strategy to fulfil this important role.

\section{Service provider}

From the pitch presentations of service providers, it could be learned that service providers were all well-prepared to face the $0 \mathrm{~A}$ movement. However, of course, they are distinguished by different service offers. The services range from full-service packages, especially for OA publishers, that enable the outsourcing of numerous process steps, such as proofreading and cover creation, to modular workflow and software packages that support the media-neutral and automated publication of academic content. One of the participating service providers also offers publishing software, but it is specialized in the needs of university presses. As part of a BMBF-funded project, the service 
provider is currently developing an online platform for $\mathrm{OA}$ publications that is modular and scalable, to provide research institutions and universities of all sizes an instrument for publishing their research.

\section{OA funding institutions}

The pitch presentations of the stakeholder group $O A$ funding institutions show another facet of the OA landscape. One participating $0 \mathrm{~A}$ funding institution revealed that patronising $0 \mathrm{~A}$ could mean, on the one hand, conveying the importance of this movement to the academic community and also supporting greater visibility of content of all subjects, and, on the other hand, working on concrete funding models for publishing houses and libraries and thus aiming to make academic content freely accessible to everyone worldwide.

The pitch presentations show clearly that the academic publication landscape is highly heterogeneous. This status quo is reflected in the challenges and wishes of the stakeholders that they also stated in their pitch presentations. Depending on the general regulations of the institutions, the challenges of $\mathrm{OA}$ publishing and wishes differ by institution. However, all stakeholders try to open their OA strategies to Open Science. In the next chapter, the stakeholders' wishes and current as well as future challenges are summarised.

\section{Challenges and wishes regarding $0 \mathrm{~A}$ publishing}

\section{University Presses}

First, the participating university presses agree that they want more cooperation and exchange of experiences. These include not only the exchange among themselves but also, in particular, the cooperation with established academic publishers in questions of financing and organisation. Furthermore, the university presses, in principle, face four key challenges that need to be overcome to be able to publish $0 \mathrm{~A}$ books efficiently.

First, the challenges include the increase in visibility and dissemination of $\mathrm{OA}$ content. For university presses, it is especially important to improve metadata management. This means the process of generating, fostering and providing metadata to discovery services and $0 \mathrm{~A}$ organisations, such as DOAB, OAPEN, OASPA, Scopus, Cope and AEUP, ideally, in one step, has to be improved and requires appropriate metadata import and export interfaces. Additionally, several university presses are working on integration of ORCID identifiers in their repository, the creation of organisational identifiers and the improvement of access statistics of e-book downloads.

Second, the participating university presses want to offer further electronic formats alongside PDF files and need software to manage the publishing workflow. For this purpose, workflow management software and web-based text editors with the possibility of annotating and commenting have to be evaluated.

Additionally, for several presses, further challenging tasks are the development of author guidelines and checklists, templates for LaTeX, InDesign and/or Microsoft Word, cost calculation for authors, and the full translation of their websites in German and English. 
Finally, the university presses are faced with organisational challenges, such as meeting the growing demand with sufficient staff, developing new job descriptions and supplying special funds for the new staff, or adopting $0 \mathrm{~A}$ journals into university presses' portfolios.

\section{Established academic publishers}

In contrast to university presses, the established academic publishers are particularly confronted with the question as to the role they want to play in the $0 \mathrm{~A}$ movement alongside the university presses. Publishers stated that they wanted to cooperate with the university presses, too, to remain central figures in $\mathrm{OA}$ publishing.

\section{Academic libraries}

For the academic libraries, more specifically, the library of the University of Applied Science Leipzig, the most important and challenging task is to consider how they can support 0A publishing because of the large volume of information and the number of approaches and projects. In other words, the library aims to develop an $\mathrm{OA}$ strategy at first. Moreover, a sustainable infrastructure has to be built, expertise of publishing has to be acquired, and research data management has to be developed. Last but not least, the public publications funds have to be used, and own funds have to be provided for $\mathrm{OA}$ publications.

\section{Service provider}

The services providers strive to consistently offer suitable and state-of-the-art services to university presses and established academic publishers. This means that service providers have to work continuously on extending their academia-focused services, workflow systems and open source business models.

\section{OA funding institutions}

Of course, the biggest challenge of OA funding institutions is to develop BPC-free funding models. In addition, the institutions prefer fixed $O A$ budgets and the intensified promotion of transparency for all kinds of research. The OA funding institutions also mentioned the desire for more exchange of experience. Moreover, they wish for an improvement of analysis tools and usage reporting for $\mathrm{OA}$ content for libraries and publishing houses.

\section{Summary of the Discussion}

Following the pitch presentations, the stated challenges and issues were collected on flashcards. In an open discourse, the keywords on flashcards were presented and discussed to match keywords to topic areas. In the discussion with the stakeholders, five topic areas could be identified. In the following chapter, the contributions of the stakeholders to various topic areas are summarised. As was already realised during the discussion, not every keyword could be clearly assigned to a topic area. 

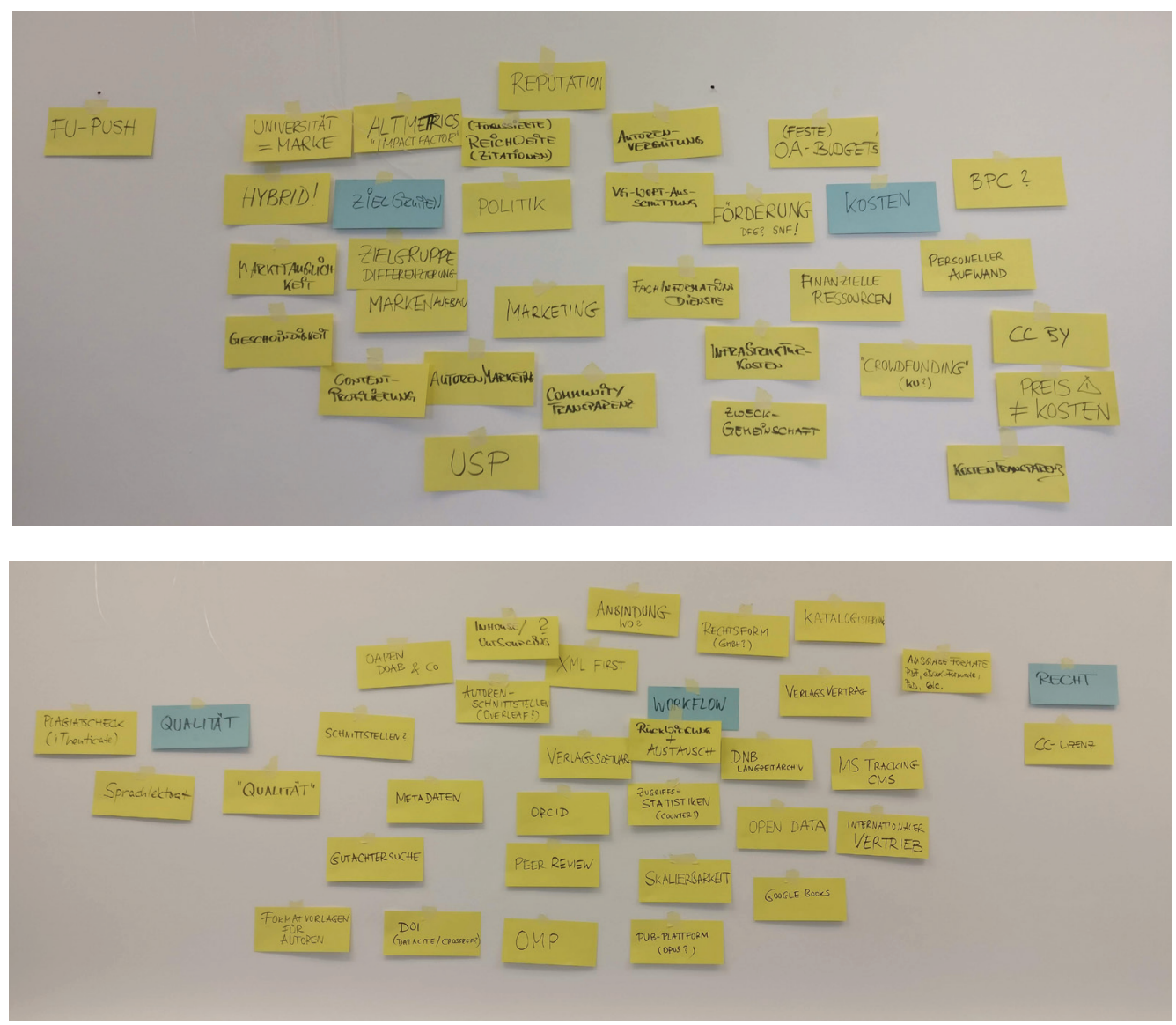

Fig. 1: Flashcards with keywords during the discussion

\section{Target groups}

In the context of the topic area target groups, the discussion focused on questions such as whether it was necessary to identify the relevant target group for books in advance and whether special marketing for $0 \mathrm{~A}$ books was necessary to guarantee a certain level of merchantability. Furthermore, authors were identified as a key target group, leading to the observation that, in particular, publishing houses had to know the authors' preferences. Moreover, a question was raised whether information services were also a target group.

In the context of this topic area, the discussion often focused on university presses and niche publishers as brands; hence, a topic area of the same name was added.

\section{Branding}

In this context, first, the stakeholders argued that a publisher's brand had a significant effect on the dissemination of content. Hence, questions were raised as to whether universities could be wellknown brands and how important it was for university presses to identify their USPs. Furthermore, the discussion revealed that there was no alternative for books to the Impact Factor. It is still up for discussion whether Altmetrics are an alternative. Additionally, it was discussed whether university 
presses were existence-threatening for niche publishers and to what extent they competed with well-established publishers.

\section{Costs}

In the context of the topic area Costs, the discussion was predominantly focused on the wishes of the stakeholders. Once again, the wish for fixed budgets for $\mathrm{OA}$ books was mentioned, as well as more cooperation between university presses and well-established publishers. In this context, the idea of a partnership of convenience between university presses and established publishers was discussed. The idea is that this partnership can reduce, for instance, the costs of infrastructure and payroll. Furthermore, the stakeholders debated the processes for which a service provider would have to be assigned, and the advantages and disadvantages of various corporate structures, business models, funding models and price and product policies.

\section{Quality}

The majority of the keywords that were assigned to the topic area Quality described activities that guaranteed the quality of content, such as peer review, language polishing service or templates for authors. However, the improvement of metadata, interfaces and the usage of software were also discussed in this context. Above all, the stakeholders agreed that, first, it was important to define what quality actually meant.

\section{Workflow}

The topic area Workflow is highly linked with quality because the improvement of workflow usually also means the improvement of quality. Thus, the discussion in this context focused on technical support. The discussion covered the software's potential to improve the publishing workflow, the locations of interfaces to be established for distribution in the workflow process, the advantages and disadvantages of in-house publishing and outsourcing, and various approaches to media-neutral publishing.

\section{Law}

In the context of the topic area Law, the discussion was focused on the different approaches of university presses and established publishers to the rights of use and the CC licences.

\section{Discussion}

The stakeholders' pitch presentations confirmed our observation that a highly heterogeneous publication landscape existed at the time. This observation implies that, first, the aim of our research project has to be to analyse the existing publishing workflows and abstract generally valid processes that are needed for media-neutral and both cost-effective and personnel-efficient publishing of $0 \mathrm{~A}$ books. The challenge will be to distinguish between the individual issues of university presses and general problems that affect all stakeholders. This means we have to evaluate the stakeholders' experiences and decide which of them are applicable to the development of an ideal and transferable publication workflow for $\mathrm{OA}$ books. Additionally, the pros and cons of the mentioned aspects, such as 
the different organisational structure of university presses or the cooperation with service providers, need to be considered more closely.

Moreover, the discussion with the stakeholders revealed further aspects of $0 \mathrm{~A}$ book publishing that had to be investigated. In addition, it was observed that the different topics and issues of OA book publishing were highly linked and that they could not be separated clearly. Accordingly, our aim has to be to integrate these issues in our research project and also try to reduce the complexity. After this, we will be able to develop a generally valid workflow for $\mathrm{OA}$ book publishing.

\section{Conclusion and Outlook}

The chosen method of a stakeholder meeting was applied to achieve the set aims in an open-minded way. This open approach allowed us to expand the research field for the project yet also categorise it into core issues. We obtained numerous insights from the meeting and will continue to involve the stakeholders in our research. As has already been mentioned, the meetings' results will contribute to the development of the ideal publishing workflow for $\mathrm{OA}$ books.

In the future stages of the project, we plan to evaluate, improve and ultimately implement the developed workflow. To this end, five books will be published by a newly founded university press at the University of Applied Science in Leipzig, Germany.

\section{Acknowledgments}

The authors wish to thank the participating stakeholders that jointed the meeting and helped us determine the presented results.

This work is funded by the Federal Ministry of Education and Research (BMBF, Germany) in the project OA-Hochschulverlag (project number 160A045).

\section{References}

Collins and Milloy (2016): OAPEN-UK final report: A five-year study into open access monograph publishing in the humanities and social sciences. p. 21. Retrieved August 01, 2018, from http:// oapen-uk.jiscebooks.org/files/2016/01/0APEN-UKfinal-report.pdf

Directory of Open Access Books: https://www.doabooks.org/. Retrieved July 16, 2018

Directory of Open Access Journals: https://doaj.org/. Retrieved July 16, 2018

Ferwerda (2014): Open access monograph business models. Insights 27, p. 35-38

Ferwerda, Snijder et al. (2018): OAPEN-CH - The impact of open access on scientific monographs in Switzerland. p. 7. Swiss National Science Foundation, Bern 


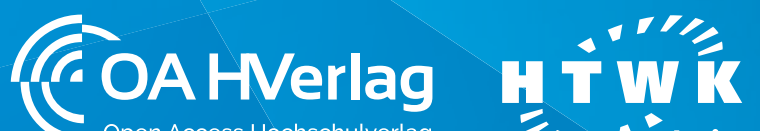

Humboldt-Universität zu Berlin: https://www.hu-berlin.de/en/research/kooperationen/kooperationsformen/an-institute. Retrieved July 30, 2018

Ojennus (2017): Open access and the humanities - The case of classics journals. Library Resources \& Technical Services 61(2), p. 81-92

Open Monograph Press: https://pkp.sfu.ca/omp/. Retrieved July 30, 2018

Uniform requirements for manuscripts submitted to biomedical journals: Writing and editing for biomedical publication. Journal of Pharmacology \& Pharmacotherapeutics 1, (1) 42 (2010). Retrieved August 01, 2018 from https://www.ncbi.nlm.nih.gov/pmc/articles/PMC3142758/

Vogel and Kupferschmidt (2017): A bold open-access push in Germany could change the future of academic publishing. Retrieved August 02, 2018 from http://www.sciencemag.org/news/2017/08/ bold-open-access-push-germany-could-change-future-academic-publishing

Ware and Mabe (2015): The STM Report, 4th edition. International Association of Scientific, Technical and Medical Publishers, Den Haag (2015). p. 89 